\title{
Studi Penerapan Area Traffic Control System (ATCS) Di Beberapa Simpang Kota Semarang (Studi Kasus Simpang PRPP Dan Madukoro)
}

\author{
Descraredo Henky Sunyoto ${ }^{1}$,Febriansyah Ramadhan ${ }^{1}$, Rudatin Ruktiningsih ${ }^{2}$ \\ Email: des.henky@gmail.com ${ }^{1}$, febrianramadhan86@gmail.com ${ }^{2}$ \\ ${ }^{1}$ Program Studi Teknik Sipil, Fakultas Teknik, Universitas Katolik Soegijapranata, Jl. \\ Pawiyatan Luhur IV/1, Bendan Dhuwur, Semarang 50234 \\ ${ }^{2}$ Dosen Program Studi Teknik Sipil, Fakultas Teknik, Universitas Katolik \\ Soegijapranata, J1. Pawiyatan Luhur IV/1, Bendan Dhuwur, Semarang 50234
}

\begin{abstract}
The increasing of transportation needs in big cities had almost a same problem, which is congestion on roads especially at the crossroads. Semarang is one of the cities located at a strategic point. Therefore, Area Traffic Control System came as a solution. Area Traffic Control System (ATCS) is a system that controlling road traffic intersections by using traffic lights where the setting of traffic light at each intersection was coordinated, so the road users could get a minimum delay. Government of Semarang plans to install ATCS at the intersection of PRPP and Madukoro. The location of study is intersections of PRPP and Madukoro, where the intersection is a cross-city connecting route that is crossed by heavy and light vehicles and vehicles that going to and out from A. Yani airport. The method that used in this study is a survey method, including surveying traffic volume, queue length, delays, and light phase. The results then processed using a formula from the Indonesian Road Capacity Guidelines (PKJI'14). The results of this study is alternative coordination with a cycle time is 244 seconds for each intersection. Intersection I starts at 0 seconds, intersection II starts at 90 seconds. The degree of saturation obtained for the north and south PRPP intersections is 0.28 , for the east is 0.36 , for the west is 0.42 , while for intersection of north Madukoro is 0.35, for the south is 0.36, for the east is 0.39, and for the west is 0. 45 So that the application of the Area Traffic Control System (ATCS) can have a positive resolution for reducing congestion and get good traffic flow in the intersections of Madukoro and PRPP.
\end{abstract}

Keywords: ATCS, Coordinated Intersection, Degree Of Saturation

\section{PENDAHULUAN}

\section{1 Latar Belakang}

Seiring berkembang pesatnya pertumbuhan kota dan pergerakan manusia, serta ruang lingkup kehidupan yang ditunjukkan dengan bertambahnya populasi penduduk, kendaraan, penghasilan dan tenaga kerja, maka permintaan akan transportasi umum maupun pribadi semakin meningkat. Ketika luas jalur lalu lintas yang digunakan tidaksebanding dengan volume kendaraan yang ada, maka akan terjadi kemacetan lalulintas. Dengan semakin meningkatnya kebutuhan transportasi di kota besar pasti memiliki 
masalah yang hampir sama, yaitu kemacetan dan tundaan pada ruas-ruas jalan terutama di persimpangan jalan.

Mengenai hal ini, untuk mengatur lalu lintas Dinas Perhubungan Kota Semarang muncul usulan untuk menggunakan suatu sistem bernama Area Traffic Control System (ATCS). Area Traffic Control System (ATCS) adalah suatu sistem pengendalian simpang lalu lintas jalan raya dengan menggunakan lampu lalu lintas (traffic light) dimana pengaturan lampu lalu lintas pada masing-masing simpang saling terkoordinasi, sehingga pengguna jalan mendapatkan tundaan yang minimum. (Wishnukoro, 2008).

Penataan siklus lampu lalu lintas dilakukan dengan ATCS berdasar input data lalu lintas yang diperoleh secara real time melalui kamera CCTV pemantau lalu lintas pada titik-titik persimpangan. Penentuan waktu siklus lampu persimpangan dapat diubah berkali-kali dalam satu hari secara efisien sesuai dengan kebutuhan lalu lintas yang mencakup keseluruhan wilayah tersebut. Penataan ritme lalu lintas akan lebih baik apabila pemerintah kota menerapkan teknologi ATCS pada semua persimpangan lalu lintas yang ada di kota tersebut. Pelaksanaan program ATCS ini mulai diberlakukan di Kota Semarang pada tahun 2014.

\section{2 Rumusan Masalah}

Perencanaan pemasangan sistem ATCS baru ini karena area simpang PRPP dan Madukoro merupakan jalur penghubung antar kota yang dilewati banyak kendaraan berat maupun ringan dan juga menjadi arus keluar masuk kendaraan dari bandara A. Yani yangsemula berada di persimpangan Kalibanteng. Belajar dari pengalaman saat arus keluar masuk bandara masih berada di persimpangan Kalibanteng yang berpotensi akan terjadinya kemacetan, maka pihak Dinas Perhubungan Kota Semarang perlu menerapkan sistem ATCS di persimpangan PRPP dan Madukoro yang akan menjadi arus keluar masuk bandara A. Yani.

\section{3 Tujuan Penelitian}

Tujuan dari studi penerapan ini adalah sebagai berikut :

1. Untuk mengetahui kondisi existing sebelum terpasangnya Area Traffic Control System (ATCS) di simpang PRPP dan Madukoro.

2. Untuk mengetahui kondisi simpang setelah dipasang Area Traffic Control System (ATCS) ditinjau dari waktu tundaan, fase lampu, panjang antrian dan volume kendaraan.

3. Menghitung fase lampu yang optimal untuk Area Traffic Control System (ATCS) sesuai dengan standart Pedoman Kapasitas Jalan Indonesia 2014 (PKJI'14) di persimpangan PRPP dan Madukoro.

\subsection{Manfaat Penelitian}

Manfaat studi penerapan ini adalah sebagai berikut :

1. Menambah pengetahuan tentang Area Traffic Control System (ATCS)

2. Penelitian ini dapat digunakan sebagai salah satu masukan bagi Dinas Perhubungan Kota Semarang dan Pemerintah Kota Semarang dalam hal merancang atau pengoperasian dari Area Traffic Control System (ATCS).

\section{TINJAUAN PUSTAKA}

\section{1 Lalu Lintas}

Pengertian lalu lintas yang terdapat dalam Undang-undang No. 22 Tahun 2009 tentang lalu lintas dan angkutan jalan yang didefinisikan sebagai gerak kendaraan dan orang di ruang lalu lintas jalan. Ruang lalu lintas jalan yang dimaksud adalah prasarana yang diperuntukkan baik gerak pindah kendaraan, orang, dan/atau barang yang 
berupa jalan dan fasilitas pendukung. Mengendalikan pergerakan orang dan atau kendaraan agar bisa berjalan dengan lancar dan aman diperlukan perangkat peraturan perundangan yang sebagai dasar dalam hal ini.

\subsection{Manajemen Lalu Lintas}

Menurut Alamsyah (2008), manajemen lalu lintas adalah suatu proses pengaturan dan penggunaan sistem jalan yang sudah ada dengan tujuan untuk memenuhi suatu kepentingan tertentu, tanpa perlu penambahan atau pembuatan infrastruktur baru.

\subsection{Persimpangan}

Persimpangan adalah simpul pada jaringan jalan di mana jalan-jalan bertemu dan lintasan kendaraan berpotongan. Lalu lintas pada masingmasing kaki persimpangan bergerak secara bersama-sama dengan lalu lintas lainnya. Berbagai persimpangan merupakan faktor-faktor yang paling penting dalam menentukan kapasitas dan waktu perjalanan pada suatu jaringan jalan, khususnya di daerahdaerah perkotaan (Departemen Perhubungan Direktorat Jenderal Perhubngan Darat, 1996).

\section{3. 1 Jenis Simpang}

Menurut Morlok (1991), dilihat dari bentuknya ada 2 macam jenis persimpangan, yaitu :

1. Pertemuan atau persimpangan jalan sebidang

2. Pertemuan atau persimpangan jalan tidak sebidang

Menurut Morlok (1988), jenis simpang berdasarkan cara pengaturannya dapat dikelompokkan menjadi 2 jenis, yaitu :

1. Simpang jalan tanpa sinyal

2. Simpang jalan dengan sinyal

\section{3. 2 Persimpangan dengan Sinyal} Lalu Lintas

Menurut Direktorat Jenderal Bina Marga dalam Manual Kapasitas Jalan
Indonesia (1997), pada umumnya penggunaan sinyal lalu lintas pada persimpangan dipergunakan untuk satu atau lebih alasan berikut ini :

a. Untuk menghindari kemacetan simpang akibat adanya konflik arus lalu lintas, sehingga terjamin bahwa suatu kapasitas tertentu dapat dipertahankan, bahkan selama kondisi lalu lintas jam puncak

b. Untuk memberi kesempatan kepada kendaraan dan/atau pejalan kaki dari jalan simpang (kecil) untuk memotong jalan utama

c. Untuk mengurangi jumlah kecelakaan lalu lintas akibat tabrakan antara kendaraan-kendaraan dari arah yang bertentangan.

\section{3. 3 Kondisi Arus Lalu Lintas}

Kondisi arus lalu lintas terdapat data lalu lintas yang dibagi dalam beberapa tipe kendaraan antara lain kendaraan tidak bermotor, sepeda motor (SM), kendaraan ringan (KR), kendaraan berat $(\mathrm{KB})$.

\section{3. 4 Kinerja Simpang}

Menurut Mc Shane dan Roess (1990) menyatakan bahwa untuk mengevaluasi kinerja suatu persimpangan, secara umum dapat dilihat dari beberapa parameter sebagai berikut :

a. Tundaan (delay)

b. Jumlah berhenti (number of stop)

c. Panjan antrian (queue length)

\section{3. 5 Pengendalian Simpang}

Menurut Abubakar, dkk. (1995), sasaran yang harus dicapai pada pengendalian persimpanan antara lain :

a. Mengurangi atau menghindari kemungkinan terjadinya kecelakaan yang disebabkan oleh adanya titiktitik konflik seperti berpencar (diverging), bergabung (merging), berpotongan (crossing), dan bersilangan (weaving) 
b. Menjaga agar kapasitas persimpangan operasinya dapat optimal sesuai dengan rencana

Harus memberikan petunjuk yang jelas dan pasti serta sederhana, dalam mengarahkan arus lalu lintas yang menggunakan persimpangan.

\section{3. 6 Simpang Bersinyal}

Simpang bersinyal adalah simpang yang dikendalikan oleh sinyal . Sinyal adalah semua peralatan pengatur yang menggunakan tenaga listrik, rambu dan marka jalan untuk mengarahkan atau memperingatkan pengemudikendaraan bermotor, pengendara sepeda, atau pejalan kaki. (Wishnukoro, 2008).

\section{3. 7 Data Masukan Lalu Lintas}

Data arus lalu lintas hanya tersedia dalam LHRT (Lalu Lintas Harian Rata-Rata Tahunan) dan dikoversikan melalui perkalian faktor $\mathrm{k}$. $\mathrm{QJD}=\mathrm{k} \times \mathrm{LHRT} \ldots . . \ldots \ldots . . .(2.1)$

Keterangan :

QJD = Volume lalu lintas harian ratarata tahunan (skr/hari)

$\mathrm{k}=$ faktor jam rencana ditetapkan dari kajian fluktuasi arus lalu lintas berdasarkan jam selama satu tahun.

Nilai $\mathrm{k}$ yang dapat digunakan untuk jalan perkotaan berkisar antara 7\% sampai dengan $12 \%$

\section{3. 8 Arus Jenuh Dasar}

Arus jenuh dapat dihitung dengan rumus :

$\mathrm{S}=\mathrm{S}_{0} \times \mathrm{FHS} \times \mathrm{FM} \times \mathrm{FUK} \times \mathrm{FG} \times \mathrm{FP} \times$

$\mathrm{FBKi} \times \mathrm{FBKa}$

Keterangan:

$\mathrm{S} \quad=$ arus jenuh (skr/jam)

$\mathrm{S}_{0} \quad=$ arus jenuh dasar (skr/jam)

FUK = faktor penyesuaian ukuran

kota

FHS = faktor penyesuaian tipe lingkungan

jalan dan gangguan samping

$\mathrm{FG} \quad=$ faktor penyesuaian kelandaian memanjang pendekat
FP = faktor penyesuaian jarak garis henti

pada mulut pendekat terhadap

kendaraan yang parkir pertama

$\mathrm{FBKi}$ = faktor penyesuaian belok kiri

$\mathrm{FBKa}=$ faktor penyesuaian belok kanan

Untuk pendekat terlindung $\mathrm{S}_{0}$

ditentukan oleh persamaan sebagai

fungsi dari lebar efektif pendekat,

dengan rumus :

$\mathrm{S}_{0}=600 \times \mathrm{LE}$

\section{3. 9 Penetapan Waktu Siklus}

Penentuan waktu siklus untuk sistem kendali waktu tetap yang dapat dilakukan menggunakan rumus Webster (1966).

$\mathrm{c}=\frac{\left(1.5 \times \mathrm{H}_{\mathrm{H}}+5\right)}{1-\sum \mathrm{R}_{\mathrm{Q}} \mathrm{S}}$

Keterangan:

c = waktu siklus (detik)

$\mathrm{H}_{\mathrm{H}} \quad$ = jumlah waktu hijau hilang per siklus (detik)

$\mathrm{R}_{\mathrm{Q} / \mathrm{S}}=$ rasio arus, yaitu arus dibagi arus jenuh, $\mathrm{Q} / \mathrm{S}$

$\mathrm{R}_{\mathrm{Q} / \mathrm{S} \text { kritis }}=$ Nilai $\quad \mathrm{R}_{\mathrm{Q} / \mathrm{S}}$ yang tertinggi dari semua pendekat yang berangkat pada fase yang sama

$\sum \mathrm{R}_{\mathrm{Q} / \mathrm{S} \text { kritis }}=$ rasio arus simpang (sama dengan jumlah semua $\mathrm{R}_{\mathrm{Q} / \mathrm{S}}$ kritis dari semua fase pada siklus tersebut)

Tabel 2. 2 Waktu Siklus yang Layak

\begin{tabular}{|c|c|}
\hline $\begin{array}{c}\text { Tipe } \\
\text { Pengaturan }\end{array}$ & $\begin{array}{c}\text { Waktu Siklus yang } \\
\text { Layak (detik) }\end{array}$ \\
\hline $\begin{array}{c}\text { Pengaturan } \\
\text { dua-fase }\end{array}$ & $40-80$ \\
\hline $\begin{array}{c}\text { Pengaturan } \\
\text { tiga-fase }\end{array}$ & $50-100$ \\
\hline $\begin{array}{c}\text { Pengaturan } \\
\text { empat-fase }\end{array}$ & $80-130$ \\
\hline
\end{tabular}

Sumber : PKJI (2014)

\section{3. 10 Menentukan Waktu Hijau}

Menurut Pedoman Kapasitas Jalan Indonesia 2014, untuk menghitung waktu hijau digunakan rumus. 
$\mathrm{Hi}=\left(\mathrm{c}-\mathrm{H}_{\mathrm{H}}\right) \times \frac{\mathrm{R}_{\mathrm{Q} / \mathrm{S} \mathrm{kritis}}}{\sum i\left(\mathrm{R}_{\mathrm{Q} / \mathrm{S} \text { kritis }}\right) \mathrm{i}} \cdots$

Keterangan :

$\mathrm{Hi}=$ waktu hijau pada fase $\mathrm{i}$ (detik)

2. 3. 11 Kapasitas Simpang Bersinyal

Kapasitas simpang (C) dirumuskan seperti pada persamaan

$\mathrm{C}=\mathrm{S} \times \frac{H}{C}$

Keterangan :

$\mathrm{C}=$ kapasitas simpang (skr/jam)

$\mathrm{S} \quad=$ arus jenuh (skr/jam)

$\mathrm{H}=$ total waktu hijau dalam satu siklus

(detik)

c = waktu siklus (detik)

\section{3. 12 Derajat Kejenuhan}

Untuk menghitung besarnya nilai derajat kejenuhan digunakan rumus.

$\mathrm{D}_{\mathrm{J}}=\frac{Q}{C}$.

Nilai derajat kejenuhan untuk simpang adalah $\leq 0,85$ sebagai batas kelayakan jalan menurut PKJI 2014.

\section{3. 13 Rasio Arus $\left(R_{Q / S}\right)$}

Untuk menghitung rasio arus digunakan rumus:

$\mathrm{R}_{\mathrm{Q} / \mathrm{S}}=\frac{Q}{S}$

2. 3. 14 Faktor Penyesuaian Khusus untuk

\section{Pendekatan Tipe $\mathbf{P}$}

Untuk menghitung faktor penyesuaian akibat lalu lintas belok kanan digunakan rumus.

$\mathrm{FBKA}=1,0+\mathrm{RBKA} \times 0,26 \ldots$ (2. 9)

Sedangkan, untuk menghitung faktor penyesuaian akibat lalu lintas belok kiri digunakan rumus.

$\mathrm{FBKI}=1,0+\mathrm{RBKI} \times 0,16 \ldots$ (2. 10)

\section{3. 15 Faktor Penyesuaian Ukuran}

Kota

Faktor penyesuaian ukuran kota

$\left(\mathrm{F}_{\mathrm{UK}}\right)$ dibedakan berdasarkan ukuran populasi penduduk, dapat dilihat pada Tabel 2. 3.
Tabel 2. 3 Faktor Penyesuaian Ukuran Kota

\begin{tabular}{|c|c|}
\hline $\begin{array}{c}\text { Jumlah } \\
\text { Penduduk Kota } \\
\text { (Juta Jiwa) }\end{array}$ & $\begin{array}{c}\text { Faktor } \\
\text { Penyesuaian } \\
\text { Ukuran Kota } \\
\left(\mathrm{F}_{\text {UK }}\right)\end{array}$ \\
\hline$>3,0$ & 1,05 \\
\hline $1,0-3,0$ & 1,00 \\
\hline $0,5-1,0$ & 0,94 \\
\hline $0,1-0,5$ & 0,83 \\
\hline$<0,1$ & 0,82 \\
\hline
\end{tabular}

Sumber : PKJI (2014)

\section{4 Menghitung Kinerja Lalu Lintas Simpang APILL}

\section{4. 1 Panjang Antrian}

Panjang antrian dihitung dengan menggunakan rumus.

$\mathrm{N}_{\mathrm{Q}}=\mathrm{N}_{\mathrm{Q} 1}+\mathrm{N}_{\mathrm{Q} 2} \ldots \ldots \ldots \ldots$

Jika nilai $\mathrm{D}_{\mathrm{J}}>0,5$, maka nilai

$\mathrm{N}_{\mathrm{Q} 1}=0.25 \times \mathrm{c} \times$

$\left\{\left(D_{J}-1\right)^{2}+\sqrt{\left(D_{J}-1\right)^{2}+\frac{8 \times\left(\mathrm{D}_{\mathrm{J}}-0.5\right)}{\mathrm{c}}}\right\}$

Apabila diketahui derajat kejenuhan DJ $\leq 0,5$, maka nilai NQ1 $=0$

$\mathrm{N}_{\mathrm{Q} 2}=\mathrm{c} \times \frac{\left(1-R_{H}\right)}{\left(1-R_{H} \times D_{J}\right)} \times \frac{\mathrm{Q}}{3600} \ldots \ldots$.
$\mathrm{PA}=\mathrm{N}_{\mathrm{Q}} \times \frac{20}{\mathrm{~L}_{\mathrm{M}}} \ldots \ldots \ldots \ldots \ldots$.

\section{4. 2 Rasio Kendaraan Terhenti}

Rasio kendaraan terhenti ( $\left.\mathrm{R}_{\mathrm{KH}}\right)$ tersebut dihitung menggunakan rumus :

$\mathrm{R}_{\mathrm{KH}}=0.9 \times \frac{\mathrm{N}_{\mathrm{Q}}}{\mathrm{Q} \times c} \times 3600$

Keterangan :

$\mathrm{N}_{\mathrm{Q}}=$ jumlah rata-rata antrian kendaraan (skr) pada awal isyarat hijau

c = waktu siklus (detik)

Q = arus lalu lintas dari pendekat yang ditinjau (skr/jam)

Jumlah rata-rata kendaraan berhenti $\left(\mathrm{N}_{\mathrm{H}}\right)$ dihitung menggunakan rumus :

$\mathrm{N}_{\mathrm{H}}=\mathrm{Q} \times \mathrm{R}_{\mathrm{KH}}$

\subsection{Tundaan}

Tundaan lalu lintas rata-rata dihitung dengan rumus PKJI 2014 yaitu sebagai berikut

$\mathrm{Ti}=\mathrm{Tli}+\mathrm{Tgi}$ 
Tundaan lalu lintas rata-rata (TL) pada suatu pendekat dapat dihitung dengan rumus 2-18.

$\mathrm{T}_{\mathrm{L}}=c \times \frac{0,5 \times\left(1-R_{H}\right)^{2}}{\left(1-R_{H} \times D_{J}\right.}+\frac{N_{Q 1}}{c} \times 3600 \ldots$ ..(2.18)

Tundaan geometri dapat dihitung dari rumus.

$\mathrm{TG}=\left(1-\mathrm{R}_{\mathrm{KH}}\right) \times \mathrm{P}_{\mathrm{B}} \times 6+\left(\mathrm{R}_{\mathrm{KH}} \times 4\right) \ldots$ ......(2. 19)

Keterangan :

$\mathrm{P}_{\mathrm{B}}=$ porsi kendaraan membelok pada suatu pendekat

\section{5 Data Kondisi Arus Lalu Lintas}

Data arus lalu lintas meliputi:

1) Arus lalu lintas per jenis kendaraan bermotor dan tak bermotor ( $q K R$, qKB, qSM, qKTB) dengan distribusi gerakan LRS, BKa, dan BKi. Tuliskan data arus ini pada masingmasing pendekat (U,S,T,B) ataupun sub-pendekat (U1,U2,dst. ).

2) Konversikan arus kedalam satuan skr/jam. Gunakan nilai ekr pada Tabel B. 2. Lampiran B.

3) Rasio arus kendaraan belok kiri (RBKi) dan rasio arus belok kanan (RBKa) untuk masingmasing pendekat.

$\begin{aligned} \mathrm{R}_{\mathrm{BKi}} & =\frac{Q_{\text {BKi }}}{Q_{\text {Total }}} \ldots \ldots \ldots \ldots \ldots(2.20) \\ \mathrm{R}_{\mathrm{BKi}} & =\frac{Q_{\text {BKa }}}{Q_{\text {Total }}} \ldots \ldots \ldots \ldots \ldots(2.21)\end{aligned}$

4) Rasio kendaraan tak bermotor (RKTB) untuk masing-masing pendekat.

$\mathrm{R}_{\mathrm{BKi}}=\frac{Q_{K T B}}{Q_{K T B}+Q_{K B T}} \ldots \ldots \ldots$

2. 6 Alat Pemberi Isyarat Lalu Lintas (APILL)

Lampu lalu lintas menurut UU no. 22/2009 tentang lalu lintas dan angkutan jalan ialah alat pemberi isyarat lalu lintas atau (APILL) merupakan lampu yang mengendalikan arus lalu lintas yang terpasang di persimpangan jalan, tempat penyeberangan pejalan kaki (zebra cross), dan tempat arus lalu lintas lainnya.

\subsection{Sistem Kerja Lampu Lalu Lintas}

Lampu lalu lintas bekerja secara otomatis dengan menggunakan sistem yang disebut ATCS (Area Traffic Control System). Sistem ini digunakan dalam rangka mengatasi kemacetan lalu lintas

\subsection{Durasi Lampu Lalu Lintas}

Durasi lampu lalu lintas dan skenario nyala lampu lalu lintas diatur dengan lama durasi sekitar 30 detik lampu hijau untuk masing - masing jalur. Durasi nyala dari masing-masing lampu diatur secara bergiliran.

\subsection{Defenisi Kepadatan Lalu Lintas}

Kepadatan merupakan ukuran penting untuk mengetahui kualitas arus lalu lintas di suatu jalan raya. Kepadatan juga menjadi salah satu parameter penting dalam aliran lalu lintas. Kepadatan lalu lintas juga tidak bisa terlepas dari volume kendaraan. Volume kendaraan dan kepadatan memperlihatkan bahwa kepadatan bertambah apabila volume kendaraan juga bertambah.

\subsection{Area Traffic Control System}

Area Traffic Control System (ATCS) adalah suatu sistem pengendalian simpang lalu lintas jalan raya dengan menggunakan lampu lalu lintas (traffic light) dimana pengaturan lampu lalu lintas pada masing-masing simpang saling terkoordinasi, sehingga pengguna jalan mendapatkan tundaan yang minimum.

\subsection{Software VISSIM Version 9. 00- 03 (Student)}

Pada pemodelan Lalu Lintas menggunakan Aplikasi yang digunakan dalam mengolah data Lalu Lintas yaitu Program software VISSIM 9. 00-03 (Student). Adapun pengertian dari VISSIM 9. 00-03 (Student) Menurut PTV-AG (2016), "Verkehr Stadten SIMulationsmodell" atau yang lebih dikenal dengan VISSIM adalah perangkat lunak simulasi aliran 
mikroskopis untuk model Lalu Lintas perkotaan.

\section{METODE PENELITIAN}

\subsection{Lokasi Penelitian}

Lokasi yang menjadi studi kasus pada penelitian ini adalah Simpang PRPP dan simpang Madukoro di Jalan Pantura Kota Semarang Provinsi Jawa Tengah. Gambar dari lokasi penelitian dapat dilihat pada gambar 3. 1 yang merupakan dari simpang PRPP dan Madukoro.

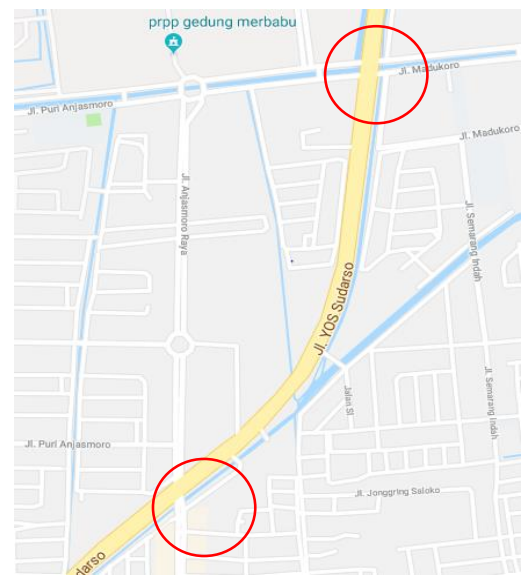

Gambar 3. 1 Lokasi Penelitian Simpang PRPP dan Madukoro

\section{2 Pengumpulan Data}

Data - data yang diperlukan dalam penelitian ini berasal dari beberapa survei diantaranya data sekunder yaitu berupa data dari instansi seperti data penduduk Kota Semarang dan tundaan lampu lalu lintas, serta data primer yang meliputi data volume lalu lintas, tundaan, panjang antrian, dan fase lampu lalu lintas yang didapat dari survei di lapangan.

\section{3 Pengambilan Data Primer}

Ada beberapa point dalam pengambilan data primer yaitu :

a) Survei Volume Lalu Lintas

b) Survei Tundaan dan Panjang Antrian

c) Survei Fase Lampu

d) Survei Waktu Siklus

e) Survei Kendaraan Henti

\section{4 Pengambilan Data Sekunder}

Data sekunder didapat dari instansi pemerintahan terkait, seperti data jumlah penduduk kota. Data sekunder yang dibutuhkan selanjutnya adalah data fase lampu lalu lintas yang digunakan sebelum ATCS dipasang

\section{5 Analisis}

Hasil dari survey ini berdasarkan pada teori yang ada dan relevan, dan dilakukan secara intensif dan dikontrol dalam pelaksanaannya. Hasil dari penelitian ini akan dianalisis dan dibandingkan dengan standart teori yang berada di buku panduan. Dengan begitu, maka akan terlihat keberhasilan pemasangan ATCS di persimpangan tersebut.

\subsection{Bagan Penelitian}

Tahapan yang dilakukan dalam penelitian ini dapat dilihat dalam bagan di bawah ini.

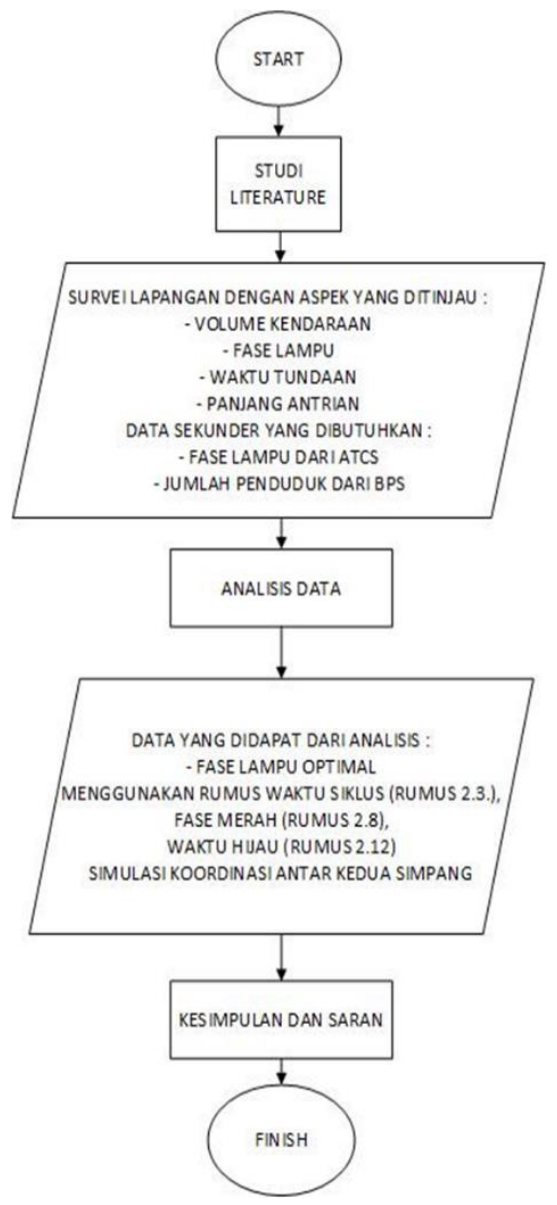


3.7 Pemodelan Simulasi Lalu Lintas dengan Menggunakan PTV Vissim 9. 0

Pemodelan simulasi lalu lintas dengan menggunakan PTV Vissim 9. 0 dilakukan setelah data volume kendaraan, fase lampu, waktu tundaan, dan panjang antrian didapatkan.

\section{HASIL PENELITIAN DAN PEMBAHASAN}

\section{1 Hasil Penelitian}

Hasil dalam penelitian pada 2 simpang di kota Semarang yakni simpang PRPP dan Madukoro merupakan hasil dari metode survey yang telah dilakukan secara langsung. Survey yang telah dilakukan meliputi survey volume lalu lintas, survey panjang antrian, dan survey fase lampu

Hasil penelitian menunjukkan bahwa terjadi kenaikan volume kendaraan dan penurunan volume kendaraan yang cukup signifikan. Kenaikan volume kendaraan sebesar 15,4\% terjadi pada Simpang Madukoro sedangkan penurunan sebesar $4 \%$ terjadi pada Simpang PRPP.

\section{2 Analisis dan Pembahasan}

Tabel 4. 2. 1 Rekapitulasi Derajat

Kejenuhan Sebelum dan Sesudah Pemasangan ATCS

\begin{tabular}{|c|c|c|c|c|c|c|c|c|}
\hline \multirow{3}{*}{ Simpang } & \multicolumn{6}{|c|}{ Sebelum ATCS } & \multicolumn{5}{|c|}{ Sesudah ATCS } \\
\cline { 2 - 9 } & \multicolumn{3}{|c|}{ Derajat Kejenuhan } \\
\cline { 2 - 9 } & Senin & Selasa & Jumat & Sabtu & Senin & Selasa & Jumat & Sabtu \\
\hline Madukoro Utara & 0,464 & 0,572 & 0,642 & 0,634 & 0,581 & 0,550 & 0,517 & 0,608 \\
\hline Madukoro Timur & 0,623 & 0,654 & 0,482 & 0,448 & 0,488 & 0,669 & 0,624 & 0,574 \\
\hline Madukoro Selatan & 0,334 & 0,374 & 0,353 & 0,371 & 0,450 & 0,434 & 0,408 & 0,292 \\
\hline Madukoro Barat & 0,366 & 0,377 & 0,461 & 0,463 & 0,475 & 0,460 & 0,507 & 0,516 \\
\hline PRPP Utara & 0,686 & 0,747 & 0,825 & 0,699 & 0,662 & 0,622 & 0,607 & 0,599 \\
\hline PRPP Selatan & 0,747 & 0,735 & 0,673 & 0,704 & 0,677 & 0,595 & 0,422 & 0,551 \\
\hline PRPP Timur & 0,786 & 0,750 & 0,727 & 0,752 & 0,615 & 0,587 & 0,587 & 0,586 \\
\hline PRPP Barat & 0,692 & 0,704 & 0,773 & 0,714 & 0,614 & 0,581 & 0,674 & 0,520 \\
\hline
\end{tabular}

Dari Tabel 4. 2. 1 di atas, derajat kejenuhan mengalami peningkatan dan penurunan baik di simpang Madukoro maupun simpang PRPP. Seperti pada hari Senin saat sebelum pemasangan ATCS derajat kejenuhan berada pada angka 0,464 di Simpang Madukoro Utara dan mengalami peningkatan setelah pemasangan ATCS menjadi 0,581. Pada simpang PRPP Utara, derajat kejenuhan mengalami penurunan dari angka 0,686 saat sebelum pemasangan ATCS menjadi 0,662 saat sesudah pemasangan ATCS.

Tabel 4. 2. 2. Rekapitulasi Panjang Antrian Sebelum dan Sesudah Pemasangan ATCS

\begin{tabular}{|c|c|c|c|c|c|c|c|c|}
\hline \multirow{3}{*}{ Simpang } & \multicolumn{8}{|c|}{ Sebelum ATCS } \\
\cline { 2 - 10 } & \multicolumn{9}{|c|}{ Panjang Antrian (smp) } \\
\cline { 2 - 10 } & Senin & Selasa & Jumat & Sabtu & Senin & Selasa & Jumat & Sabuu \\
\hline Madukoro Utara & 102,466 & 92,929 & 86,239 & 76,442 & 181,403 & 173,167 & 156,819 & 53,541 \\
\hline Madukoro Timur & 62,418 & 57,767 & 51,252 & 43,795 & 87,794 & 90,560 & 81,482 & 74,602 \\
\hline Madukoro Selatan & 66,647 & 59,436 & 58,721 & 50,916 & 100,463 & 96,054 & 90,253 & 84,376 \\
\hline Madukoro Barat & 66,781 & 67,096 & 58,399 & 50,034 & 98,576 & 93,690 & 85,442 & 81,849 \\
\hline PRPP Utara & 413,832 & 407,958 & 388,824 & 386,751 & 301,240 & 177,108 & 153,480 & 156,516 \\
\hline PRPP Selatan & 786,221 & 747,447 & 682,361 & 717,376 & 489,938 & 415,874 & 323,690 & 360,659 \\
\hline PRPP Timur & 517,591 & 495,341 & 467,845 & 480,579 & 197,205 & 174,277 & 156,430 & 149,799 \\
\hline PRPP Barat & 385,332 & 377,317 & 360,437 & 360,557 & 157,918 & 190,727 & 164,075 & 166,780 \\
\hline
\end{tabular}

Dari Tabel 4. 2. 2 di atas, panjang antrian mengalami peningkatan dan penurunan baik di simpang Madukoro maupun simpang PRPP. Seperti pada hari Senin saat sebelum pemasangan ATCS panjang antrian berada pada angka 102,466 smp di Simpang Madukoro Utara dan mengalami peningkatan setelah pemasangan ATCS menjadi 181,403 smp. Pada simpang PRPP Utara, panjang antrian mengalami penurunan dari angka 413,832 smp saat sebelum pemasangan ATCS menjadi 301,240 smp saat sesudah pemasangan ATCS.

Tabel 4. 2. 3 Rekapitulasi Tundaan Sebelum dan Sesudah Pemasangan ATCS

\begin{tabular}{|c|c|c|c|c|c|c|c|c|}
\hline \multirow{2}{*}{ Simpang } & \multicolumn{6}{|c|}{ Sebelum ATCS } & \multicolumn{5}{|c|}{ Sesudah ATCS } \\
\cline { 2 - 10 } & \multicolumn{9}{|c|}{ Tundaan (smp/detik) } \\
\cline { 2 - 9 } & Senin & Selasa & Jumat & Sabtu & Senin & Selasa & Jumat & Sabtu \\
\hline Madukoro Utara & 22,477 & 20,783 & 20,788 & 22,631 & 30,818 & 30,753 & 31,088 & 12,707 \\
\hline Madukoro Timur & 13,251 & 12,800 & 12,003 & 12,218 & 13,494 & 15,277 & 15,256 & 15,143 \\
\hline Madukoro Selatan & 15,863 & 14,282 & 16,015 & 16,736 & 18,659 & 18,686 & 20,175 & 20,800 \\
\hline Madukoro Barat & 13,422 & 13,940 & 13,502 & 13,804 & 15,501 & 15,425 & 15,577 & 16,556 \\
\hline PRPP Utara & 35,419 & 36,943 & 38,954 & 36,558 & 28,224 & 26,265 & 27,228 & 27,583 \\
\hline PRPP Selatan & 63,596 & 64,152 & 62,883 & 63,503 & 44,742 & 43,306 & 36,603 & 43,904 \\
\hline PRPP Timur & 59,887 & 60,088 & 62,260 & 61,148 & 25,699 & 25,864 & 28,486 & 25,787 \\
\hline PRPP Barat & 43,755 & 45,821 & 49,615 & 46,102 & 21,329 & 22,009 & 22,416 & 22,628 \\
\hline
\end{tabular}

Dari Tabel 4. 2. 3 di atas, tundaan mengalami peningkatan dan penurunan baik di simpang Madukoro maupun simpang PRPP. Seperti pada hari Senin saat sebelum pemasangan ATCS tundaan berada pada angka 22,477 smp/detik di Simpang Madukoro Utara dan mengalami peningkatan setelah pemasangan ATCS menjadi 30,818 smp/detik. Pada simpang PRPP Utara, tundaan mengalami penurunan dari 
angka 35,419 smp/detik saat sebelum pemasangan ATCS menjadi 28,224 smp/detik saat sesudah pemasangan ATCS.

\section{3 Koordinasi dan Simulasi}

Berdasarkan perhitungan pada Subbab 4. 2. maka dapat dihasilkan 3 simulasi perhitungan untuk dapat menentukan koordinasi antar 2 simpang. Ketiga simulasi tersebut dapat dilihat pada Tabel 4. 3. 1 hingga Tabel 4. 3.3

Tabel 4. 3. 1 Simulasi 1 antara Simpang Madukoro hingga Simpang PRPP

\begin{tabular}{|c|c|c|c|c|c|c|c|c|c|c|}
\hline \multicolumn{10}{|c|}{ SIMULASI1 } & \multirow{3}{*}{ Kriteria } \\
\hline \multirow{2}{*}{ Simpang } & \multirow{2}{*}{ Pendekat } & \multicolumn{4}{|c|}{ Waktu Siklus } & \multirow{2}{*}{ Total } & \multirow{2}{*}{\begin{tabular}{|c|}
$\mathrm{PA}$ \\
meter \\
\end{tabular}} & \multirow{2}{*}{\begin{tabular}{|l|} 
Tundaan \\
det $/$ mp \\
\end{tabular}} & \multirow{2}{*}{\begin{tabular}{c|} 
Derajat \\
Kejenuhan
\end{tabular}} & \\
\hline & & All red & Merah & Kuning & Hijau & & & & & \\
\hline \multirow{4}{*}{ Madukoro } & UTARA & 3 & 236 & 2 & 29 & \multirow{4}{*}{299} & 121,653 & 15,029 & 0,360 & BAGUS \\
\hline & SELATAN & 3 & 262 & 2 & 16 & & 393,738 & \begin{tabular}{|l|}
59,303 \\
\end{tabular} & 1,535 & TIDAKBAGUS \\
\hline & TIMUR & 3 & 254 & 2 & 20 & & 327,000 & \begin{tabular}{|l|}
37,817 \\
\end{tabular} & 1,513 & TIDAKBAGUS \\
\hline & BARAT & 3 & 262 & 2 & 16 & & 307,224 & \begin{tabular}{|l|}
35,658 \\
\end{tabular} & 1,569 & TIDAKBAGUS \\
\hline \multirow{4}{*}{ PRPP } & UTARA & 3 & 252 & 2 & 21 & \multirow{4}{*}{299} & 222,977 & \begin{tabular}{|l|}
22,156 \\
\end{tabular} & 0,662 & BAGUS \\
\hline & SELATAN & 3 & 242 & 2 & 26 & & 494,994 & \begin{tabular}{|l|}
44,553 \\
\end{tabular} & 0,677 & BAGUS \\
\hline & TIMUR & 3 & 226 & 2 & 34 & & 210,680 & 27,292 & 0,615 & BAGUS \\
\hline & BARAT & 3 & 244 & 2 & 25 & & 197,172 & \begin{tabular}{|l|}
25,851 \\
\end{tabular} & 0,614 & BAGUS \\
\hline
\end{tabular}

Simulasi 1 memiliki waktu siklus sebesar 299 detik namun pada kaki simpang Madukoro Selatan, Timur, dan Barat besar derajat kejenuhan lebih dari 0,85 sehingga simulasi ini tidak bagus untuk diaplikasikan karena akan menimbulkan tundaan yang besar jika dikoordinasikan.

Tabel 4. 3. 2. Simulasi 2 antara Simpang Madukoro hingga Simpang PRPP

\begin{tabular}{|c|c|c|c|c|c|c|c|c|c|c|}
\hline \multicolumn{10}{|c|}{ SIMULASI2 } & \multirow{3}{*}{ Kriteria } \\
\hline \multirow{2}{*}{ Simpang } & \multirow{2}{*}{ Pendekat } & \multicolumn{4}{|c|}{ Waktu Siklus } & \multirow{2}{*}{ Total } & \multirow{2}{*}{\begin{tabular}{|c|}
$\mathrm{PA}$ \\
meter \\
\end{tabular}} & \multirow{2}{*}{\begin{tabular}{|l|} 
Tundaan \\
det $/$ mp
\end{tabular}} & \multirow{2}{*}{\begin{tabular}{|c|c|} 
Derajat \\
Kejenuhan
\end{tabular}} & \\
\hline & & All red & \begin{tabular}{|l|} 
Merah \\
\end{tabular} & \begin{tabular}{|l|} 
Kuning \\
\end{tabular} & Hijau & & & & & \\
\hline \multirow{4}{*}{ Madukoro } & UTARA & 3 & 132 & 2 & 26 & \multirow{4}{*}{189} & \begin{tabular}{|l|}
45,106 \\
\end{tabular} & 5,227 & 0,219 & BAGUS \\
\hline & SELATAN & 3 & 158 & 2 & 13 & & \begin{tabular}{|l|}
72,517 \\
\end{tabular} & 10,786 & 0,394 & BAGUS \\
\hline & TIMUR & 3 & 150 & 2 & 17 & & 400,345 & 46,007 & 1,822 & TIDAK BAGUS \\
\hline & BARAT & 3 & 158 & 2 & 13 & & 206,737 & 24,485 & 1,100 & TIDAK BAGUS \\
\hline \multirow{4}{*}{ PRPP } & UTARA & 3 & 148 & 2 & 18 & \multirow{4}{*}{189} & \begin{tabular}{|l|}
112,020 \\
\end{tabular} & \begin{tabular}{|l|}
11,092 \\
\end{tabular} & 0,403 & BAGUS \\
\hline & SELATAN & 3 & 138 & 2 & 23 & & \begin{tabular}{|l|}
29,377 \\
\end{tabular} & \begin{tabular}{|l|}
3,247 \\
\end{tabular} & 0,174 & BAGUS \\
\hline & TIMUR & 3 & 122 & 2 & 31 & & \begin{tabular}{|l|}
266,579 \\
\end{tabular} & \begin{tabular}{|l|}
35,308 \\
\end{tabular} & 0,740 & BAGUS \\
\hline & BARAT & 3 & 140 & 2 & 22 & & \begin{tabular}{|l|}
120,586 \\
\end{tabular} & \begin{tabular}{|l|}
15,132 \\
\end{tabular} & 0,431 & BAGUS \\
\hline
\end{tabular}

Simulasi 2 memiliki waktu siklus sebesar 189 detik namun pada kaki simpang Madukoro Timur dan Barat besar derajat kejenuhan lebih dari 0,85 sehingga simulasi ini tidak bagus untuk diaplikasikan karena akan menimbulkan tundaan yang besar jika dikoordinasikan.
Tabel 4. 3. 3 Simulasi 3 antara Simpang Madukoro hingga Simpang PRPP

\begin{tabular}{|c|c|c|c|c|c|c|c|c|c|c|}
\hline \multicolumn{10}{|c|}{ SIMULASI3 } & \multirow{3}{*}{ Kriteria } \\
\hline \multirow{2}{*}{ Simpang } & \multirow{2}{*}{ Pendekat } & \multicolumn{4}{|c|}{ Waktu Siklus } & \multirow{2}{*}{ Total } & \multirow{2}{*}{\begin{tabular}{|c|}
$P A$ \\
meter \\
\end{tabular}} & \multirow{2}{*}{$\begin{array}{l}\text { Tundaan } \\
\text { det/smp }\end{array}$} & \multirow{2}{*}{$\begin{array}{c}\text { Derajat } \\
\text { Kejenuhan }\end{array}$} & \\
\hline & & All red & Merah & Kuning & Hijau & & & & & \\
\hline \multirow{4}{*}{ Madukoro } & UTARA & 3 & 183 & 2 & 28 & \multirow{4}{*}{244} & \begin{tabular}{|l|}
167,805 \\
\end{tabular} & \begin{tabular}{ll|}
19,082 \\
\end{tabular} & 0,350 & BAGUS \\
\hline & SELATAN & 3 & 189 & 2 & 25 & & \begin{tabular}{|l|}
160,178 \\
\end{tabular} & 18,693 & 0,365 & BAGUS \\
\hline & TIMUR & 3 & 201 & 2 & 19 & & \begin{tabular}{|l|}
186,514 \\
\end{tabular} & 17,360 & 0,394 & BAGUS \\
\hline & BARAT & 3 & 209 & 2 & 15 & & \begin{tabular}{|l|}
181,333 \\
\end{tabular} & \begin{tabular}{|l|l|}
18,112 \\
\end{tabular} & 0,454 & BAGUS \\
\hline \multirow{4}{*}{ PRPP } & UTARA & 3 & 199 & 2 & 20 & \multirow{4}{*}{244} & \begin{tabular}{|l|}
110,562 \\
\end{tabular} & 8,995 & 0,284 & BAGUS \\
\hline & SELATAN & 3 & 189 & 2 & 25 & & \begin{tabular}{|l|}
138,203 \\
\end{tabular} & \begin{tabular}{|l|l|}
10,507 \\
\end{tabular} & 0,284 & BAGUS \\
\hline & TIMUR & 3 & 175 & 2 & 32 & & \begin{tabular}{|l|}
197,433 \\
\end{tabular} & 20,602 & 0,364 & BAGUS \\
\hline & BARAT & 3 & 191 & 2 & 24 & & \begin{tabular}{|l|l|}
189,536 \\
\end{tabular} & 21,834 & 0,426 & BAGUS \\
\hline
\end{tabular}

Simulasi 3 memiliki waktu siklus sebesar 244 detik dengan derajat kejenuhan pada tiap kaki simpang kurang dari 0,85 . Hasil panjang antrian dan tundaan juga menghasilkan angka yang baik sehingga simulasi 3 merupakan simulasi terbaik daripada simulasi 1 dan simulasi 2 karena berdasarkan PKJI 2014 jika derajat kejenuhan pada suatu kaki simpang lebih dari 0,85 maka simpang tersebut perlu untuk dilakukan perubahan desain yang berkaitan dengan penetapan fase dan waktu isyarat, lebar pendekat, atau membuat perhitungan baru.

Dalam perencanaan ini, digunakan kecepatan rata-rata existing sebesar 40 $\mathrm{km} / \mathrm{jam}$. Kecepatan rencana ini dipilih karena cukup memenuhi kecepatan maksimum kendaraan dalam kota sesuai standar yang berlaku saat ini. Kendaraan dengan kecepatan yang lambat akan menghasilkan waktu offset yang panjang sehingga kendaraan terakhir dalam platoon masih memiliki kesempatan untuk mendapatkan waktu hijau dan tidak perlu untuk menunggu waktu hijau dalam satu siklus lagi. Waktu tempuh antar simpang Madukoro dan simpang PRPP adalah : $t=\frac{\operatorname{Jarak}(S)}{\operatorname{Kecepatan}(v)}=\frac{1,1(\mathrm{~km})}{40\left(\frac{\mathrm{km}}{\mathrm{jam}}\right)}=0,0275$ jam

$$
=1,65 \text { menit }=99 \text { detik }
$$

Sehingga dapat direncanakan koordinasi antar simpang PRPP dan Madukoro dengan waktu siklus 244 detik dan waktu offset 99 detik. Perencanaan ini direncanakan agar 
kendaraan yang bergerak dengan kecepatan yang lambat atau kurang dari $40 \mathrm{~km} / \mathrm{jam}$ dapat mengalami fase hijau saat mencapai simpang kedua baik dari arah simpang Madukoro maupun simpang PRPP.

\section{KESIMPULAN DAN SARAN 5. 1 Kesimpulan}

Terdapat beberapa hal yang dapat disimpulkan dari studi penerapan serta hasil analisis yang sudah dilakukan adalah sebagai berikut :

1. Kondisi existing sebelum pemasangan ATCS di simpang PRPP dan simpang Madukoro menunjukkan derajat kejenuhan yang cukup baik, yaitu di angka 0,47 di kaki simpang Madukoro Barat, 0,42 di kaki simpang Madukoro Timur, 0,34 di kaki simpang Madukoro Utara dan Selatan. Derajat kejenuhan pada kondisi existing simpang PRPP memiliki angka yang cukup baik, yaitu 0,68 di kaki simpang PRPP Utara, 0,74 di kaki simpang PRPP Selatan, 0,78 di kaki simpang PRPP Timur, dan 0,69 di kaki simpang PRPP Barat.

2. Dalam penelitian ini, terjadi peningkatan volume lalu lintas pada simpang Madukoro dari 2845 kendaraan menjadi 3284 kendaraan, sehingga terjadi peningkatan volume kendaraan sebesar 15,4\% sedangkan pada simpang PRPP terjadi penurunan volume kendaraan dari 4451 kendaraan menjadi 4269 kendaraan, sehingga terjadi penurunan sebesar $4 \%$.

3. Kondisi simpang setelah dilakukan pemasangan ATCS di simpang PRPP dan simpang Madukoro menunjukkan peningkatan derajat kejenuhan. Besar derajat kejenuhan di simpang Madukoro yaitu 0,58 di kaki simpang Madukoro Barat, 0,48 di kaki simpang Madukoro Timur, 0,45 di kaki simpang Madukoro Utara, dan 0,47 di kaki simpang Madukoro Selatan sedangkan untuk simpang PRPP juga mengalami peningkatan derajat kejenuhan yaitu 0,66 di kaki simpang PRPP Utara, 0,67 di kaki simpang PRPP Selatan, 0,61 di kaki simpang PRPP Timur dan Barat.

4. Kondisi simpang setelah dilakukan pemasangan ATCS di simpang Madukoro dan simpang PRPP menunjukkan waktu tundaan yang stabil dan menurun. Sebelum dilakukannya pemasangan ATCS, tundaan untuk kaki simpang Madukoro Utara di simpang Madukoro adalah 15,702 det/smp sedangkan setelah pemasangan ATCS tundaan tersebut menurun menjadi 15,508 det/smp sedangkan tundaan untuk simpang PRPP mengalami penurunan dari 64,12 $\mathrm{det} / \mathrm{smp}$ menjadi 21,32 $\mathrm{det} / \mathrm{smp}$ untuk kaki simpang PRPP Utara.

5. Kondisi panjang antrian untuk simpang Madukoro mengalami peningkatan, dari 72,17 smp untuk kaki simpang Madukoro Utara meningkat menjadi 98,57 smp sedangkan simpang PRPP mengalami penurunan dari 427,65 smp menjadi 157,91 smp untuk kaki simpang PRPP Utara.

6. Data dari kedua simpang tersebut diolah kembali untuk dijadikan simulasi. Simulasi ini digunakan untuk mengkoordinasikan kedua simpang tersebut sehingga mengurangi tundaan dan panjang antrian. Dari pengolahan data tersebut, dihasilkan tiga simulasi. Ketiga simulasi tersebut menghasilkan waktu siklus yang berbeda, simulasi 1 menghasilkan waktu siklus 299 detik, simulasi 2 
menghasilkan 189 detik, dan simulasi 3 menghasilkan 244 detik.

7. Dari ketiga simulasi tersebut menghasilkan derajat kejenuhan yang berbeda-beda untuk tiap kaki simpang. Dari derajat kejenuhan tersebut dipilih simulasi 3 karena menghasilkan derajat kejenuhan kurang dari 0,85 untuk tiap kaki simpang sedangkan untuk simulasi 1 dan simulasi 2 memiliki derajat kejenuhan lebih dari 0,85 untuk beberapa kaki simpang.

8. Koordinasi antar simpang menghasilkan waktu offset (waktu tempuh antar 2 simpang dengan kecepatan rencana $40 \mathrm{~km} / \mathrm{jam}$ ) antar 2 simpang yaitu 99 detik. Hal ini dilakukan dengan cara membuat kedua simpang memiliki waktu siklus yang sama yaitu 244 detik. Dari waktu offset dan waktu siklus tersebut akan terbentuk lintasan tidak terkena sinyal merah sehingga dapat memperkecil derajat kejenuhan serta panjang antrian pada masing-masing kaki simpang.

9. Peak hour dalam sehari terjadi pada pagi hari dan sore hari. Setelah dilakukan perencanaan waktu siklus baru untuk koordinasi, kinerja kedua simpang menjadi lebih baik dengan melakukan perubahan waktu siklus.

\subsection{Saran}

Dari kesimpulan tersebut, terdapat beberapa saran yang dapat usulkan, yaitu :

1. Dalam Penelitian ini harus dicheck kembali derajat kejenuhan tundaan dan pengaturan siklus selama 3 bulan sekali.

2. Penelitian ini dapat dilanjutkan dan diterapkan kembali pada simpangsimpang yang lain supaya mengurangi angka kemacetan di Kota Semarang.
DAFTAR PUSTAKA

Direktur Jenderal Perhubungan Darat. 1996. Pedoman Teknis Pengaturan Lalu Lintas di Persimpangan Berdiri Sendiri dengan Alat Pemberi Isyarat Lalu Lintas. Departemen Perhubungan.

Jatmiko, Wahyu. 2013. Analisis Dampak Pemasangan ATCS TerhadapEmisi Gas Buang( $\mathrm{CO}_{2}$ ) di Jl. Jend. Sudirman Kota Tangerang. Semarang: Biro Penerbit Planologi Undip.

Kementrian Pekerjaan Umum. 2014. Pedoman Kapasita Simpang APILL. Departemen Pekerjaan Umum.

Magfirona, Alfia. 2014. The Delays for Signalized Intersection Using ATCS Data and Field Surve Method. Surakarta : Universitas Muhammadiyah Surakarta.

Manto. 2014. Perangkat Pengatur Timer Lampu Lalu Lintas Berdasarkan Antrian Kendaraan. Depok : Universitas Indonesia.

Munandar, Aris. Persepsi Masyarakat Terhadap Alat Pemberi Isyara tLalu Lintas (APILL) Sistem Counter Down Traffic Light dalam Menciptakan Perilaku Tertib Berkendara di Kota Yogyakarta. Yogyakarta : Universitas Negeri Yogyakarta.

Prasetyo, Sigit. Kinerja Dinas Perhubungan Kota Bandar Lampung dalam Pelaksanaan Program ATCS (Area Traffic Control System) di Kota Bandar Lampung. Lampung : Universitas Lampung.

Rahman, Rahmatang. 2010. Analisa Dampak Lalu Lintas (Studi Kasus Kemacetan di Jalan Ngael Madya Surabaya). Palu : Universitas Tadulako.

Republik Indonesia. 2015. Peraturan Menteri Perhubungan Republik 
Indonesia Nomor PM 26 Tahun 2015 Tentang Standar Keselamatan Lalu Lintas dan Angkutan Jalan. Menteri Perhubungan Republik Indonesia.

Republik Indonesia. 2015. Peraturan

Direktur Jenderal Perhubungan Darat Nomor SK. 2343/KP. 108/DRD/2015 Tentang

Kompetensi Pengelolaan Sistem Alat Pemberi Isyarat Lalu Lintas Terkoordinasi (Area Traffic Control System). Dinas Perhubungan Darat

Saputra, Ronal Merza. 2014. Analisis Perencanaan Penerapan Area Traffic Control System di Kota Pangkal Pinang. Palembang : Universitas Sriwijaya.

Sutandi, Caroline. 2007. Evaluasi Kinerja dari Sistem Penendalian Lalu Lintas Kawasan pada Persimpangan Bersinyal dengan Banyak Fase dan Pergerakan. Bandung : Universitas Katolik Parahyangan.

Syndhuwardhana, Felisiano, dkk. Pengendalian ATCS dengan CCTV Dinamis Melalui Port Parallel. Semarang : Universitas Katolik Soegijapranata.

Tarigan, Tam saka Artoka dan Surbakti, Medis S. Simulasi Koordinasi Rambu Lalu Lintas Terhadap Volume Kendaraan Saat Waktu PuncakLalu Lintas di Persimpangan Menggunakan Software Vissim. Medan : Universitas Sumatera Utara

Wells, GR. 1993. Rekayasa Lalu Lintas. Jakarta : Penerbit Bhratara diterjemahkan oleh Ir. Suwardjoko Warpani.

Wijayanto, Bambang. 2017 . Manajemen Pemantauan Lalu Lintas pada Persimpangan Jalan di Denpasar. Bali : STMIK Stikom Bali.
Wishnukoro. 2008. Analisis Simpang Empat Bersinyal Dengan Menggunakan Manajemen Lalu Lintas. Tugas Akhir. JTS. FTSPUII. Yogyakarta

Yossyafra dan Fauziah, Syifa. 2016. Studi Integrasi Area Traffic Control System melalui Koordinasi Persimpangan pada Ruas Jalan Aziz Chan dan Jendral Sudirman sebagai Jalur Emergency Kota Padang. Padang : Universitas Andalas 